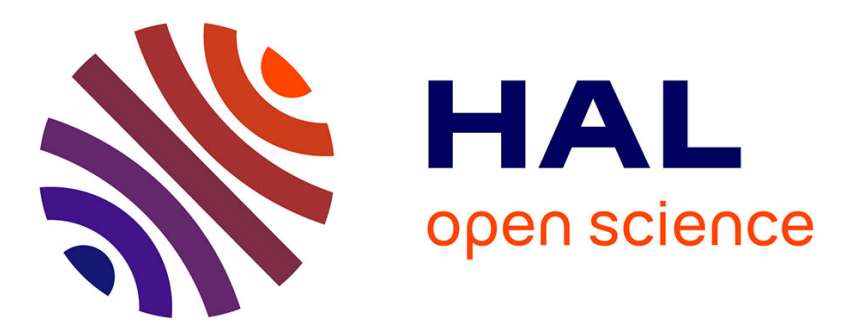

\title{
Lyotropic liquid crystals and linear supramolecular polymers of end-functionalized oligosaccharides
}

Teemu Myllymäki, Aynur Guliyeva, Antti Korpi, Mauri Kostiainen, Ville Hynninen, Nonappa Nonappa, Patrice Rannou, Olli Ikkala, Sami Halila

\section{- To cite this version:}

Teemu Myllymäki, Aynur Guliyeva, Antti Korpi, Mauri Kostiainen, Ville Hynninen, et al.. Lyotropic liquid crystals and linear supramolecular polymers of end-functionalized oligosaccharides. Chemical Communications, 2019, 55 (78), pp.11739-11742. 10.1039/C9CC04715H . hal-02998259

\section{HAL Id: hal-02998259 \\ https://hal.science/hal-02998259}

Submitted on 10 Nov 2020

HAL is a multi-disciplinary open access archive for the deposit and dissemination of scientific research documents, whether they are published or not. The documents may come from teaching and research institutions in France or abroad, or from public or private research centers.
L'archive ouverte pluridisciplinaire $\mathbf{H A L}$, est destinée au dépôt et à la diffusion de documents scientifiques de niveau recherche, publiés ou non, émanant des établissements d'enseignement et de recherche français ou étrangers, des laboratoires publics ou privés. 


\section{Lyotropic liquid crystals and linear supramolecular polymers of end-functionalized oligosaccharides}

Received 00th January 20xx, Accepted 00th January 20xx DOI: $10.1039 / \times 0 \times x 00000 x$
Teemu T. T. Myllymäki, ${ }^{a}$ Aynur Guliyeva, $\ddagger^{b}$ Antti Korpi, ${ }^{c}$ Mauri A. Kostiainen, ${ }^{c}$ Ville Hynninen, ${ }^{c}$ Nonappa, ${ }^{a}$ Patrice Rannou, ${ }^{d}$ Olli Ikkala, ${ }^{a}$ and Sami Halila*
We synthesized permethylated maltoheptaose oligosaccharides, whose both ends have been functionalized with supramolecular binders 2-ureido-4[1H]-pyrimidinones (UPy) after single ringopening of $\beta$-cyclodextrin counterpart. In 1,1,1,3,3,3-hexafluoro-2propanol (HFIP), they show lyotropic liquid crystallinity. In the dried state they allow linear saccharide-based supramolecular polymers by UPy-dimerization.

Polysaccharides consist of a wide range of naturally occurring biopolymers, including starch and cellulose. They and their modifications have attracted a major revived interest due to their abundance, safety, diversity, and sustainability as they are not extracted from oil-based resources. ${ }^{1}$ Their classic applications are in pharmaceutics, cosmetics, foods, beverages, detergents, textiles, paper, and paint, but recently new high-tech functional application has been suggested by nanocelluloses. ${ }^{2}$

By contrast to conventional polymers with covalently connected repeat units, supramolecular polymers are based on low molecular weight repeat units, which are connected to form one dimensional arrays via supramolecular interactions. ${ }^{3-}$ 6 Therein, 2-ureido-4[1H]-pyrimidinone (UPy) is particularly feasible, undergoing dimerization by four cooperative hydrogen bonds. ${ }^{7}$ The dimerization can be controlled by solvent exchanges. ${ }^{8,9}$ More generally, UPy is also feasible in supramolecular constructions. ${ }^{10-12}$ Surprisingly, linear supramolecular polymers based on oligosaccharide building blocks have not yet been reported. Still they could allow relevant design options due to their non-covalently connected chains, e.g., to tackle the microplastic pollution problem

\footnotetext{
Department of Applied Physics, Aalto University School of Science, FI-02150, Espoo, Finland. E-mail: olli.ikkala@aalto.fi

b. Univ. Grenoble Alpes, CNRS, CERMAV, F-38000 Grenoble, France. E-mail: sami.halila@cermav.cnrs.fr

Department of Biotechnology and Chemical Technology, Aalto University, FI00076, Espoo, Finland.

d. Univ. Grenoble Alpes, CNRS, CEA, IRIG, SYMMES, F-38000 Grenoble, France.

† Electronic Supplementary Information (ESI) available: Experimental section and supporting Figs and Table. See DOI: 10.1039/x0xx00000x

$\ddagger$ Present address: Interfaces, Confinement, Matériaux et Nanostructures (ICMN) UMR 7374, CNRS-Université d'Orléans, CS 40059, F-45071 Orléans, France
}

arising from the slow degradation of oil-based covalent polymers or to develop bioactive and adaptive glycomaterials with remarkable low-temperature processability and recyclability. ${ }^{13}$

Such arguments encouraged us to explore routes for oligosaccharides where both ends are decorated with the UPy supramolecular binding motifs enabling the fabrication of supramolecular glycomaterials with promising applications. Note that this is synthetically untrivial as it is well-known that selectively reacting the nonreducing end of oligo- or polysaccharides remains very challenging. This urges us to identify key-enabling and synthetically accessible protection/deprotection paths.

On the other hand, lyotropic liquid crystal systems have been reported for various polysaccharides including cellulose, chitin, amylose or their derivatives. ${ }^{15-20}$ This has allowed specific benefits, such as improved alignment in fiber spinning. Therefore, it can be asked whether also the repeating units of polysaccharide-based supramolecular polymers could form lyotropic liquid crystals with appropriately selected processing solvents.

In this work we present a concise synthetic scheme for monodisperse oligosaccharides symmetrically end-capped with UPy quadruple hydrogen bonding (H-bonding) motifs, aiming at lyotropic liquid crystallinity and supramolecular polymers. The synthesis is illustrated in Fig. 1 and fully characterized $(\mathrm{ESI}+)$. The synthesis was achieved from the commercially available trimethyl- $\beta$-cyclodextrin (TM- $\beta C D$ ) (1), which is a derivative of amylose, or more generally, of starch. Therein the lateral $\mathrm{OH}$-groups are completely protected by permethylation. It was treated with a $30 \% \mathrm{HClO}_{4}$ aqueous solution at $0{ }^{\circ} \mathrm{C}$ and warmed up to room temperature for $6 \mathrm{~h}$ to trigger a ring opening reaction yielding a mixture of linear malto-oligomeric chains. It consisted of a majority (79\%) of maltoheptaose derivative (2) with a degree of polymerization of $7\left(D_{7}\right)$, accompanied by lower homologues $\mathrm{DP}_{6}(8 \%), \mathrm{DP}_{5}$ (6\%), $\mathrm{DP}_{4}(5 \%)$, and $\mathrm{DP}_{3}(2 \%)$, 


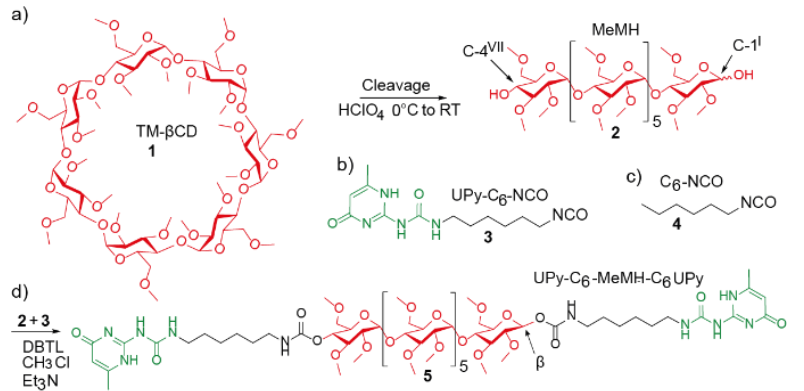

Fig. 1 The synthesis scheme. a) The reaction of permethylated $\beta$-cyclodextrin (TM- $\beta C D$ ) (1) with perchloric acid $\mathrm{HClO}_{4}$ to achieve ring-opening and liberate two free $\mathrm{OH}$ groups, one in the both ends of the permethylated maltoheptaose (MeMH) (2). b) 2-ureido$4[1 \mathrm{H}]$-pyrimidinone isocyanate with hexyl spacer (UPy- $\left.\mathrm{C}_{6}-\mathrm{NCO}\right)$ (3). c) Hexyl isocyanate $\mathrm{C}_{6}-\mathrm{NCO}(4)$, which was used as a model compound to tune the synthesis conditions, and to synthesize a reference compound for the LC formation. d) The reaction between (2) and (3) to achieve the permethylated maltoheptaose, where both ends have been equipped with UPy $4-\mathrm{H}$ bonding motifs (UPy- $\mathrm{C}_{6}-\mathrm{MeMH}-\mathrm{C}_{6}-\mathrm{UPy}$ ) (5)

calculated from the relative ratios from peak intensities in MALDI-TOF MS spectrum $(E S I+)^{21}$ The lateral methyl protection of the $\mathrm{OH}$-groups allows to perform topochemical ring-opening reactions of the two $\mathrm{OH}$ end-groups in the permethylated maltoheptaose $(\mathrm{MeMH})$, still involving the challenge to accomplish both of the end-group reactions.

The reaction conditions were first tuned using $n$-hexyl isocyanate $\mathrm{C}_{6}-\mathrm{NCO}(4)$ (Fig. 1c) to modify the two hydroxyl groups at the reducing end $\mathrm{C}-1^{\prime}$ of the maltoheptaose derivative (2), and at the nonreducing end $\mathrm{C}-4 \mathrm{VII}$. Dibutyltin dilaurate (DBTL) and $\mathrm{Et}_{3} \mathrm{~N}$ were needed to catalyze the reaction and to achieve high $\beta$-stereoselectivity ${ }^{22,23}$ for $\mathrm{C}_{6^{-}}$

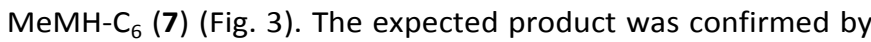
${ }^{1} \mathrm{H}$ NMR where $\beta$-stereoselectivity of the carbamate linker was observed as a doublet with a coupling constant of $J_{1,2}=8.1 \mathrm{~Hz}$ at $5.43 \mathrm{ppm}$. MALDI-TOF-MS further confirmed the bisfunctionalization where a peak at $1723.89 \mathrm{~m} / \mathrm{z}$ was detected and assignable to the molecular ion $\left(\mathrm{m} / \mathrm{z},[\mathrm{M}+\mathrm{Na}]^{+}\right)(\mathrm{ESI}+)$. Such reaction conditions were next used to react UPy- $\mathrm{C}_{6}-\mathrm{NCO}$ (3) with MeMH (2) to afford the targeted product (5). Note importantly, that the lower than $\mathrm{DP}_{7}$ oligosaccharides present in the crude mixture resulting from ring-opening of $T M-\beta C D$ (vide supra: Fig. 1a) were removed during purification by flash chromatography on silica gel (ESI + ). Finally, the synthesis yielded monodisperse permethylated maltoheptaose derivative (5), where both ends have been equipped with "sticky" UPy groups with a hexyl spacer, abbreviated as UPy$\mathrm{C}_{6}-\mathrm{MeMH}-\mathrm{C}_{6}-$ UPy (5). The hexyl linker can create hydrophobic pockets to promote UPy dimerization even in polar solvents like water. ${ }^{24-27}$ The carbamate linker between the hexyl and sugar in (5) can also mediate lateral hydrogen bonds between the neighboring molecules. Therefore, the building block (5) is reminiscent of a pentablock architecture, each block having a specific functional role. Note also, that the central MeMH block is not totally rigid, as the internal hydrogen bonds have been blocked by methylation.

The dissolution properties of UPy- $\mathrm{C}_{6}-\mathrm{MeMH}-\mathrm{C}_{6}-\mathrm{UPy}(5)$ are subtle. The molecule is poorly water-soluble. It dissolves in polar solvents such as dimethyl sulfoxide, dimethyl formamide, methanol, ethanol, and acetone. Surprisingly, UPy- $\mathrm{C}_{6}-\mathrm{MeMH}-$
$\mathrm{C}_{6}$-UPy (5) dissolves also in chloroform, toluene, and dichloromethane, despite the dimerizing UPy-groups.

Considering the liquid crystallinity, none of above solvents or their mixtures led to birefringent textures characteristic for lyotropic LCs, even if a wide range of conditions (mixtures of solvents and concentrations) were screened. Upon searching potential solvents, the previously reported lyotropic liquid crystallinity of related polysaccharides turned instructive: Halogenated acids, such as trifluoroacetic acid, allow lyotropic liquid crystallinity of methylcellulose and methylated amylose, whose chemical structures are closely related to the present MeMH. ${ }^{28-31}$ However, the strong acidity of trifluoroacetic acid ( $\mathrm{pKa}=0.3$ ) and other halogenated acids can cause degradation of the sugars. 1,1,1,3,3,3-Hexafluoro-2-propanol (HFIP) turned out, so far, the only solvent that allowed lyotropic LC of UPy$\mathrm{C}_{6}-\mathrm{MeMH}^{-\mathrm{C}_{6}-\mathrm{UPy}}$ (5). It is a strong hydrogen bonding donor, due to the strong electron-withdrawing fluorine atoms attached to the $\alpha$-carbon of the $\mathrm{OH}$ group. ${ }^{32}$ This has previously allowed dissolution of several polymeric ethers, including methylated sugars and hydrocarbons. ${ }^{33}$ However, there are two adverse properties, the safety and especially the high volatility. The high vapor pressure $\left(16 \mathrm{kPa}\right.$ at $\left.20^{\circ} \mathrm{C}\right)$ and the low boiling point $\left(58.2^{\circ} \mathrm{C}\right)$ makes it exceedingly difficult to prevent the solvent from evaporating and maintaining the desired concentrations. This limited severely quantitative characterizations.

The lyotropic liquid crystallinity of UPy- $\mathrm{C}_{6}-\mathrm{MeMH}-\mathrm{C}_{6}-\mathrm{UPy}$ (5) in HFIP was first studied using polarized optical microscopy (POM). The sample was first dissolved in HFIP at a relatively high concentration $(500 \mathrm{mg} / \mathrm{mL}$ ). It was placed between two glass slides, sealed with thermosetting acrylic glue with inherent pinholes to reduce the solvent evaporation rate (Fig. 2a). Special efforts were made to keep the sample and the sealant separate, i.e., to prevent their mixing. The HFIP solution was initially nonbirefringent (Fig. 2b). Upon a slow evaporation of HFIP through the polyacrylate sealant between the glass plates, a birefringent texture started to evolve after ca. 18h (Fig. 2c). The fact that the birefringent texture is really due to liquid crystallinity, is shown in Movie S1 ESIt, which shows flow of the texture upon poking with a spatula. After $c a$. 5 days, the birefringent $L C$ texture covered the whole sample area (Fig. 2d). After removing the cover slip and evaporating all the remaining solvent, the sample showed some residual birefringence (Fig. 2e).

The POM patterns of Fig. $2 d$ were instructive to suggest the $\mathrm{LC}$ structure of UPy- $\mathrm{C}_{6}-\mathrm{MeMH}-\mathrm{C}_{6}-\mathrm{UPy}(5)$ in HFIP. It suggests a spherulitic texture with smooth domains of a fluid columnar mesophase, nucleating from the lower concentration isotropic areas which appear black under crossed polarizers. Worth noticing is the uniaxial symmetry of these defects with bright (orange vs. blue) colored domains separated by sharp (black) isogyres defining large size (up to $c a .100 \mu \mathrm{m}$ in diameter) of Maltese crosses which follow the extinction of the analyzer/polarizer (A/P) directions. This reveals a high-quality orthogonal alignment of columnar aggregates radiating from the melatope of the Maltese crosses. Interestingly, the long- 
range order of the columnar self-assembly remained in the higher concentration spherulitic textures (Fig. 2d). A $\lambda$-wave
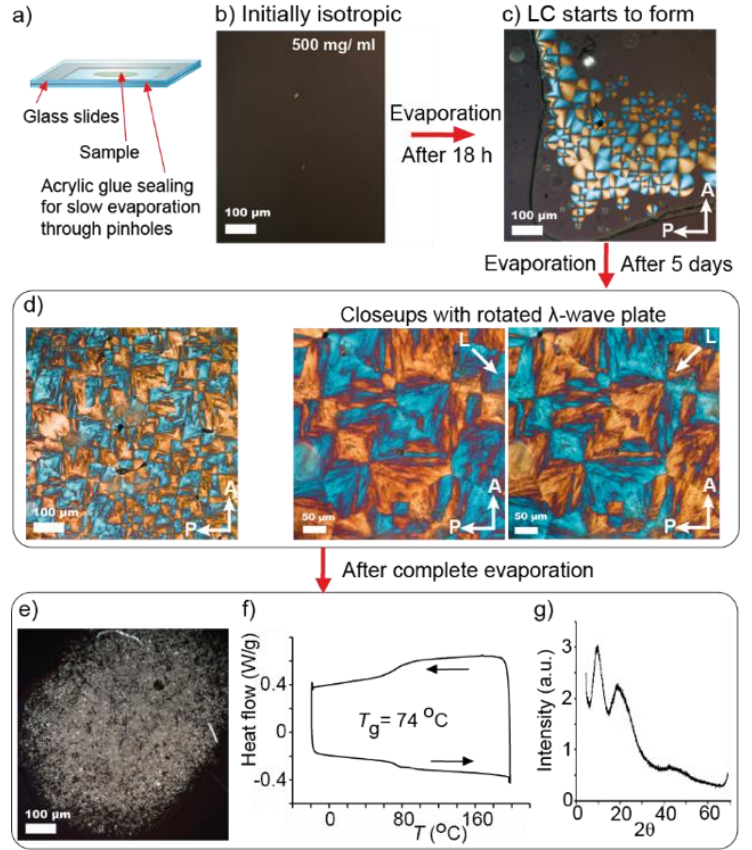

Fig. 2 The sample cell and POM images of UPy-C6-MeMH-C6-UPy 5 in HFIP. a) The sample cell allowing slow evaporation of HFIP. b) Isotropic solution (concentration of ca. $500 \mathrm{mg} / \mathrm{mL}$ ) immediately after mixing, imaged between crossed polarizers with a POM using a full $\lambda$-wave plate. c) Emergence of the first birefringent texture typical of a lyotropic columnar mesophase after $c a .18$ hours. d) Birefringent spherulitic texture covering large areas after 5 days, also illustrating the effect of the $90^{\circ}$ rotation of a ful $\lambda$-wave plate. Complete drying leads to amorphous glassy material, with some residual birefringence (e), (f) DSC indicating glass transition at $\mathrm{Tg}$ of $c a .74{ }^{\circ} \mathrm{C}$, and (g) broad XRD-peaks suggesting that crystallization does not take place.

plate discriminated the columnar aggregates aligned perpendicular and along the wave plate axis by retarding (by one full wavelength) the green component of polarized white light. Figs $2 d$ illustrate the orthogonal orientations of the axes of columnar aggregates which manifest through the inversion of orange vs. blue domains of the Maltese crosses when rotating the full $\lambda$-wave plate by $90^{\circ}$.

Incidentally these POM observations are reminiscent to those observed for the lyotropic LC mesophases of "short" 4 20 base pair $\beta$-DNA and RNA duplexes with "sticky" ends. ${ }^{34-37}$ Therein, the observed phases are the chiral nematic, uniaxial columnar, and higher-order columnar. A key feature for this behavior is the end-to-end adhesion into columnar aggregates by the sticky ends. This can only develop if a subtle balance between competing interactions exists. In the present case, the self-assembling UPy dimerize in less polar environments which the $\mathrm{C}_{6}$-linkers can provide. In the initial isotropic state with UPy- $\mathrm{C}_{6}-\mathrm{MeMH}-\mathrm{C}_{6}-\mathrm{UPy}$ (5) in HFIP, the UPy end-groups form hydrogen bonds preferentially with HFIP, instead of UPy dimerization. Upon HFIP evaporation, the balance gradually shifts towards the UPy dimerization.

After these qualitative findings, considerable efforts were made to assess the critical concentration for the appearance of the lyotropic LC mesophases. Due to the extremely volatility of HFIP, reliable estimates could not be achieved. Also, X-ray measurements were tried, however, efforts to allow controlled evaporation in time-resolved $\mathrm{X}$-ray scattering measurements
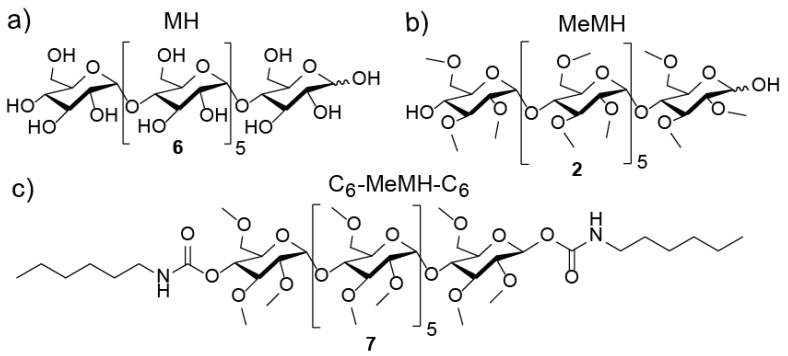

Fig. 3 Reference compounds, not leading to lyotropic liquid crystallinity (ESI†).

turned unsuccessful.

To shed light on the role of the end-group UPy-moieties, the $\mathrm{C}_{6}$-linkers, and the central MeMH-moieties on the observed mesomorphic behaviors, reference compounds were studied. Fig. 3a shows maltoheptaose $\mathrm{MH}$ with free $\mathrm{OH}$ groups (6). It was not soluble in HFIP, but was soluble in water. Permethylated maltoheptaose with $\mathrm{OH}$-end groups, $\mathrm{MeMH}$ (2), and permethylated maltoheptaose with hexyl end-groups without self-associating UPy moieties, $\mathrm{C}_{6}-\mathrm{MeMH}^{-\mathrm{C}_{6}}$ (7), were soluble in the same solvents as UPy- $\mathrm{C}_{6}-\mathrm{MeMH}-\mathrm{C}_{6}-\mathrm{UPy}(5)$. Note that none of these reference samples formed lyotropic LCs in any tested solvent or in any tried concentration and they all crystallized upon drying.

We discuss next the dried UPy- $\mathrm{C}_{6}-\mathrm{MeMH}^{-} \mathrm{C}_{6}-\mathrm{UPy}(\mathbf{5})$. Based on thermogravimetric analysis (ESI + ), the DSC measurements were limited to $200{ }^{\circ} \mathrm{C}$. The DSC curve of dried UPy- $\mathrm{C}_{6}-\mathrm{MeMH}-$ $\mathrm{C}_{6}$-UPy (5) shows a glass transition at ca. $74{ }^{\circ} \mathrm{C}$ (Fig. 2f) and no crystallization/melting transitions. WAXS of the dried sample shows only broad reflections instead sharp crystalline peaks, also indicating amorphous disordered solid with only correlation hole peaks. In conclusion, by contrast to the crystal-forming reference compounds of Fig. 3, (5) showed a tendency for glass formation and residual birefringence upon drying. It showed suppressed crystallization, suggesting kinetic trapping into anisotropic glassy state, indirectly hinting formation of polymer-like chains with free volume. This is not surprising, as the UPy dimerization is expected, when the hydrogen bond donating HFIP has evaporated. Note that the binding constant of the parallel UPy-groups is substantially smaller than that of their end-to-end arrangements, whereupon the UPy dimerization preferably leads to supramolecular polysaccharide instead of their lateral bindings. The FTIR spectra shows the $\mathrm{N}-\mathrm{H}$ stretching of carbamate at $3730-3750 \mathrm{~cm}^{-1}$ (Fig. S11 in ESI+), which can indicate lateral hydrogen bonds between the carbamates.

Importantly, UPy- $\mathrm{C}_{6}-\mathrm{MeMH}^{-\mathrm{C}_{6}}$-UPy (5) allowed to draw fibers (Figs 4d) before completely dried, which one would not expect if the supramolecular polymer does not form. However, the fibers turned brittle due to weak lateral connections between the molecules in the case of permethylated maltoheptaose. In this sense, it would be ultimately desirable to allow for a final removal of the lateral methyl-protecting group that was needed to allow the topochemical reactions at 
both ends of the maltoheptaose building block. This encourages to pursue other lateral protection schemes, still compatible with

a)

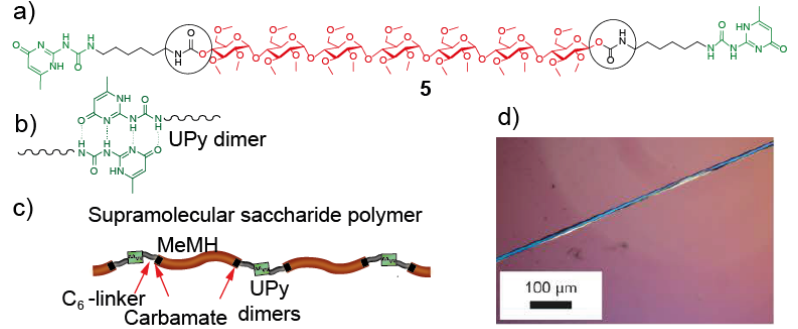

Fig. 4 a) Chemical structure of UPy- $\mathrm{C}_{6}-\mathrm{MeMH}-\mathrm{C}_{6}-\mathrm{UPy}$ 5, with highlighted carbamate groups. b) UPy 4-Hydrogen bonding dimerization. c) Schematics of the UPy- $\mathrm{C}_{6}-\mathrm{MeMH}-$ $\mathrm{C}_{6}$-UPy supramolecular polymer, indicating the supramolecular bonding sites. d)

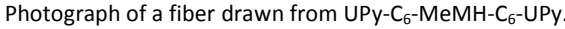

both of the end-group reactions. This issue is currently under investigation and various tracks are explored for alternative protection/deprotection paths.

In conclusion, we synthesized monodisperse permethylated maltoheptaose, where both ends have been functionalized using quadruple $\mathrm{H}$-bonding UPy motifs allowing supramolecular polymerization of this saccharide building block. Both ends were simultaneously reacted with UPy- $\mathrm{C}_{6^{-}}$ NCO (3) with high $\beta$-stereoselectivity and efficiency. UPy allows supramolecular polymerization by $\mathrm{H}$-bonding upon solvent removal. We foresee potential for linear supramolecular polysaccharides owing to the renewable and bioactive carbohydrate building-blocks and the ability to undergo reversible switching of structure, morphology, and properties under exposure to certain external stimuli.

Funding from Academy of Finland, Centre of Excellence in Molecular Engineering of Biosynthetic Hybrid Materials, and ERC Advanced Grant are acknowledged. This work made use of Aalto University Nanomicroscopy Center premises. Maria Godinho is acknowledged for useful discussions. OI, TTTM, PR, and $\mathrm{SH}$ thank Univ. Grenoble Alpes (UGA) for the partial support under the Project BioTriCo. AG, SH and PR acknowledge Polynat Carnot Institute (No. 16-CARN-025-01), Glyco@Alps project (ANR-15-IDEX-02), ICMG FR 2607 platform, UPR5301-CERMAV (CNRS/UGA), and UMR5819SYMMES (CNRS/CEA/UGA).

\section{Conflicts of interest}

The authors declare no conflict of interests.

\section{Notes and references}

1 Y. Habibi, L. A. Lucia, Eds., Polysaccharide Building Blocks, John Wiley \& Sons, Inc., Hoboken, NJ, USA, 2012.

2 E. Kontturi, P. Laaksonen, M. Linder, Nonappa, A. H. Gröschel, O. J. Rojas, O. Ikkala, Adv. Mater., 2018, 30, 1703779 .

3 L. Brunsveld, B. J. B. Folmer, E. W. Meijer, R. P. Sijbesma, Chem. Rev., 2001, 101, 4071-4098.

4 T. F. A. De Greef, E. W. Meijer, Nature, 2008, 453, 171-173.
5 T. Aida, E. W. Meijer, S. I. Stupp, Science, 2012, 335, 813817.

6 E. Krieg, M. M. C. Bastings, P. Besenius, B. Rybtchinski, Chem. Rev., 2016, 116, 2414-2477.

7 F. H. Beijer, R. P. Sijbesma, H. Kooijman, A. L. Spek, E. W. Meijer, J. Am. Chem. Soc., 1998, 120, 6761-6769.

8 S. H. M. Söntjens, R. P. Sijbesma, M. H. P. Van Genderen, E. W. Meijer, J. Am. Chem. Soc., 2000, 122, 7487-7493.

9 (a)T. T. T. Myllymäki, Nonappa, H. Yang, V. Liljeström, M. A. Kostiainen, J.-M. Malho, X. X. Zhu, O. Ikkala, Soft Matter, 2016, 12, 7159-7165; (b) K. Bertula, Nonappa, T. Myllymäki, H. Yang, X. X. Zhu, O. Ikkala, Polymer, 2017, 126, 177-187

10 O. J. G. M. Goor, S. I. S. Hendrikse, P. Y. W. Dankers, E. W. Meijer, Chem. Soc. Rev., 2017, 46, 6621-6637.

11 T. T. T. Myllymäki, L. Lemetti, Nonappa, O. Ikkala, ACS Macro Lett., 2017, 6, 210-214.

12 P. Shokrollahi, H. Mirzadeh, W. T. S. Huck, O. A. Scherman, Polymer, 2010, 51, 6303-6312.

13 P. Y. W. Dankers, M. C. Harmsen, L. A. Brouwer, M. J. A. Van Luyn, E. W. Meijer, Nat. Mater., 2005, 4, 568-574.

14 R. S. Werbowyj, D. G. Gray, Mol. Cryst. Liq. Cryst., 1976, 34, 97-103.

15 I. W. Hamley, Soft Matter, 2010, 6, 1863-1871.

16 R. D. Gilbert, P. A. Patton, Prog. Polym. Sci., 1983, 9, 115131.

17 J. F. Revol, H. Bradford, J. Giasson, R. H. Marchessault, D. G. Gray, Int. J. Biol. Macromol., 1992, 14, 170-172.

18 J. P. F. Lagerwall, C. Schütz, M. Salajkova, J. Noh, J. H. Park, G. Scalia, L. Bergström, NPG Asia Mater., 2014, 6, 1-12.

19 A. P. C. Almeida, J. P. Canejo, S. N. Fernandes, C. Echeverria, P. L. Almeida, M. H. Godinho, Adv. Mater., 2018, 30, 1703655.

20 J. P. Canejo, N. Monge, C. Echeverria, S. N. Fernandes, M. H. Godinho, Liq. Cryst. Rev., 2017, 5, 86-110.

21 Y. Ishida, G. Fukuhara, ACS Omega, 2018, 3, 6279-6282.

22 R. G. G. Leenders, R. Ruytenbeek, E. W. P. Damen, H. W. Scheeren, Synthesis (Stuttg), 1996, 11, 1309-1312.

23 L. Chen, L. Zhang, J. Chen, J. Yang, R. Li, Chinese Sci. Bull., 2010, 55, 4187-4196.

24 R. E. Kieltyka, A. C. H. Pape, L. Albertazzi, Y. Nakano, M. M. C. Bastings, I. K. Voets, P. Y. W. Dankers, E. W. Meijer, J. Am. Chem. Soc., 2013, 135, 11159-11164.

25 M. Guo, L. M. Pitet, H. M. Wyss, M. Vos, P. Y. W. W. Dankers, E. W. Meijer, J. Am. Chem. Soc., 2014, 136, 6969-6977.

26 M. Ramaekers, I. De Feijter, P. H. H. Bomans, N. A. J. M. Sommerdijk, P. Y. W. Dankers, E. W. Meijer, Macromolecules, 2014, 47, 3823-3828.

27 J. F. Xu, L. Y. Niu, Y. Z. Chen, L. Z. Wu, C. H. Tung, Q. Z. Yang, Org. Lett., 2014, 16, 4016-4019.

28 Y. Huang, B. K. Wu, S. H. Jiang, Mol. Cryst. Liq. Cryst., 1990 $188,177-187$.

29 J.-X. Guo, D. G. Gray, J. Polym. Sci. Part A, 1994, 32, 889-896.

30 D. L. Patel, R. D. Gilbert, J. Polym. Sci. Polym. Phys. Ed., 1981, 19, 1231-1236

31 O. A. Khanchich, S. A. Kuznetsova, Polym. Sci. A, 2011, 53, 311-316.

32 I. Colomer, A. E. R. Chamberlain, M. B. Haughey, T. J. Donohoe, Nat. Rev. Chem., 2017, 1, 0088.

33 W. Zhao, A. Kloczkowski, J. E. Mark, B. Erman, Chem. Mater. 1998, 10, 784-793.

34 M. Nakata, G. Zanchetta, B. D. Chapman, C. D. Jones, J. O. Cross, R. Pindak, T. Bellini, N. A. Clark, Science, 2007, 318, 1276-1279.

35 G. Zanchetta, M. Nakata, M. Buscaglia, T. Bellini, N. A. Clark Proc. Natl. Acad. Sci. U. S. A., 2008, 105, 1111-1117.

36 T. Bellini, G. Zanchetta, T. P. Fraccia, R. Cerbino, E. Tsai, G. P. Smith, Proc. Natl. Acad. Sci. U. S. A., 2012, 109, 1110-1115. 
Journal Name

37 M. Salamonczyk, J. Zhang, G. Portale, C. Zhu, E. Kentzinger, J.

T. Gleeson, A. Jakli, C. De Michele, J. K. G. Dhont, S. Sprunt, et al., Nat. Commun., 2016, 7, 13358. 